\title{
A Study to assess Depression levels in MBBS Students
}

\author{
Kaushik Patil ${ }^{1}$, Dhruvi Chande ${ }^{2}$, S.A. Pratinidhi ${ }^{3}$, Aneesh Bhat ${ }^{4}$ \\ 1-4 Department of Biochemistry and Psychiatry, MIMER Medical College, Pune, India \\ Corresponding author: S.A. Pratinidhi \\ Email-mayashilpa5@gmail.com
}

\begin{abstract}
Background and Objectives: Medical education can be quite stressful and studies all over the world have consistently shown a high prevalence of depression in medical students. In India, the prevalence of depression was around 39\%. It was observed that the prevalence of provisionally diagnosed depressive disorder and major depressive disorder in medical students was $21.5 \%$ and $7.6 \%$, respectively. Our plan is to assess the depression level in the students and according treatment will be given

Methods: The study duration of this project was 18 months. The data for this study has been collected from I year, II year and III year medical students of MIMER Medical College and B.S.T.R.H, Talegaon Dabhade. The Study design and Set-up was a cross-sectional, questionnaire-based study. Using stratified random sampling, 200 students were selected who agreed to volunteer in the project.

Results: In our study, the prevalence of depression was found to be more in $1^{\text {st }}$ year than the $2^{\text {nd }}$ and $3^{\text {rd }}$ year. This finding could be due to students' just entering medical college after high school. The other causes maybe language problem, vast syllabus, fear of failure, tight schedule and tough topics.

Conclusion: Interaction between students and faculties should be encouraged so that the signs of stress can be detected and addressed at the earliest. Prevention strategies should take into considerations the wide variety of factors that are inducing stress among students.
\end{abstract}

Keywords: Depression, stress, MBBS students.

(Paper received $-9^{\text {th }}$ April 2018, Peer review completed $-22^{\text {nd }}$ May 2018)

(Accepted $-24^{\text {th }}$ May 2018)

\section{INTRODUCTION}

Depression is one of the four major diseases in the world and is the most common cause of disability from diseases [1]. It causes severe symptoms that affect how you feel, think and handle daily activities, such as sleeping, eating, or working. To be diagnosed as depression, the symptoms must be present for at least two weeks. Some forms of depression are slightly different, or they may develop under unique circumstances, such as:

1. Persistent depressive disorder is a depressed mood that lasts for at least 2 years

2. Perinatal depression is characterized by relatively mild depressive and anxiety symptoms that typically clear within two weeks after the delivery.

3. Seasonal affective disorder is onset of depression with seasonal variation.

4. Bipolar disorder is characterized by episodes of extremely low moods followed by extreme higheuphoric state called "mania" [2].

Depression has been varied from 1.7 to 74 per thousand population, and widespread problem across the country [3]. College students are exclusive group of people that are enduring a critical transitory period in which they're going from adolescence to adulthood and can be one of the most stressful times in a person's life [4]. The major cause of anxiety can be due to reasons such as trying to fit in, maintain good grades, 
plan, and being away from home [5]. As a reaction to this stress, some students get depressed. They find that they cannot get themselves together. They may cry all the time, skip classes, or isolate themselves without realizing they're depressed [6].

The report on Global Burden of Disease estimates the point prevalence of the unipolar depressive episodes to be $1.9 \%$ for men and $3.2 \%$ for women and the one-year prevalence is estimated to be $5.8 \%$ for men and $9.5 \%$ for women. It estimated that by the year 2020 the burden of depression will increase to $5.7 \%$ of the total burden of the disease if the current trends for demographic and epidemiological transition continue. It would then be the $2^{\text {nd }}$ leading cause of disability-adjusted life years (DALYs), second only to ischemic heart disease [7].

Depression among medical students is extremely prevalent. Medical students are confronted with significant academic, psychological and existential stressors [8]. Consequently, prevalence of depression is higher in medical students compared to general population. It has been observed that mental health worsens after students begin medical school and remain poor throughout training. On a personal level, this distress can contribute to substance abuse, broken relationships, suicide and attrition from the profession. On a professional level, study suggests that student distress contributes to cynicism and subsequently may affect students' care of patients, relationship with faculty and ultimately the culture of medical profession [9].

Medical education can be quite stressful and studies all over the world have consistently shown a high prevalence of depression in medical students [10]. In India, the prevalence of depression was around 39\%. It was observed that the prevalence of provisionally diagnosed depressive disorder and major depressive disorder in medical students was $21.5 \%$ and $7.6 \%$, respectively [11].

Academic performance had a significant association with depression in medical students. The stigma associated with poor academic performance may be a contributing factor. On the other hand, students with excellent academic performance maybe facing pressures due to the competitive nature of medical education [12].

It is also seen that Medical students are reluctant to seek help from mental health services. Although $14.7 \%$ students admitted having experienced depressive symptoms, only $4.7 \%$ had ever consulted a counselor [13]. In a prior study to find prevalence of depression and use of mental health services amongst medical students, it was seen that only $22 \%$ of depressed students were using mental health counseling services. The most frequently cited barriers to using these services were lack of time, lack of confidentiality, stigma associated with using mental health services, cost, fear of documentation on academic record, and fear of unwanted intervention. Our plan is to assess the depression level in the students and according treatment will be given [13].

\section{METHODOLOGY}

This Observational Question based Cross-Sectional Study was approved by institutional ethical committee (IEC). The study duration of this project was 18 months. The data for this study has been collected from I year, II year and III year medical students of MIMER Medical College and B.S.T.R.H, Talegaon Dabhade. The Study design and Set-up was a cross-sectional, questionnaire-based study. Using stratified random sampling, 200 students were selected who agreed to volunteer in the project.

\section{Patient Health Questionnaire - 9 (PHQ-9)}

This scale is used to measure the severity of depression along with the diagnosis of depression. It is a selfadministered_tool. Patient Health Questionnaire 9 is widely used in research and clinical practice to assess depression. It was derived from the original instrument viz., Primary Care Evaluation of Mental Disorders (PRIME-MD) The PHQ-9 contains 9 items. Each item has score ranging from 0 to 3 on the LIKERT scale. The TOTAL score is 27 [14]. The PHQ- 9 has a sensitivity of $88 \%$ and a specificity of $88 \%$ for major depression when the cut-off score of 10 is taken [15].

Patient Health Questionnaire (PHQ-9), was used to make a provisional diagnosis of depression. It is a selfadministered questionnaire which will assist in screening, evaluating and provisionally diagnosing depression. Based on the PHQ-9 Depression Score of each student, Mild depressive students were given 
assisted counseling. Moderate to Severely depressive students were given treatment by the Department of Psychiatry, MIMER Medical College and B.S.T.R.H Talegaon (D)

\section{Interpretation of Total Score}

\begin{tabular}{|c|c|}
\hline TOTAL SCORE & DEPRESSION SEVERITY \\
\hline $5-9$ & Mild depression \\
\hline $10-14$ & Moderate depression \\
\hline $15-19$ & Moderately Severe depression \\
\hline $20-27$ & Severe depression \\
\hline
\end{tabular}

The total Study population was 200, out of which:

$1^{\text {st }}$ year medical students; between age group 17-19 years Total -72 .

$2^{\text {nd }}$ year medical students; between age group 18-20 years Total -82 .

$3^{\text {rd }}$ year medical students, between age group 21-22 years. Total -46 .

\section{RESULTS}

Table 1 - Gender wise distribution of students

\begin{tabular}{|c|c|c|c|}
\hline Year & Male & Female & Total \\
\hline $1^{\text {st }}$ & 32 & 40 & 72 \\
\hline $2^{\text {nd }}$ & 33 & 49 & 82 \\
\hline $3^{\text {rd }}$ & 18 & 28 & 46 \\
\hline
\end{tabular}

Table 2 - Prevalence of Depression amongst MBBS students

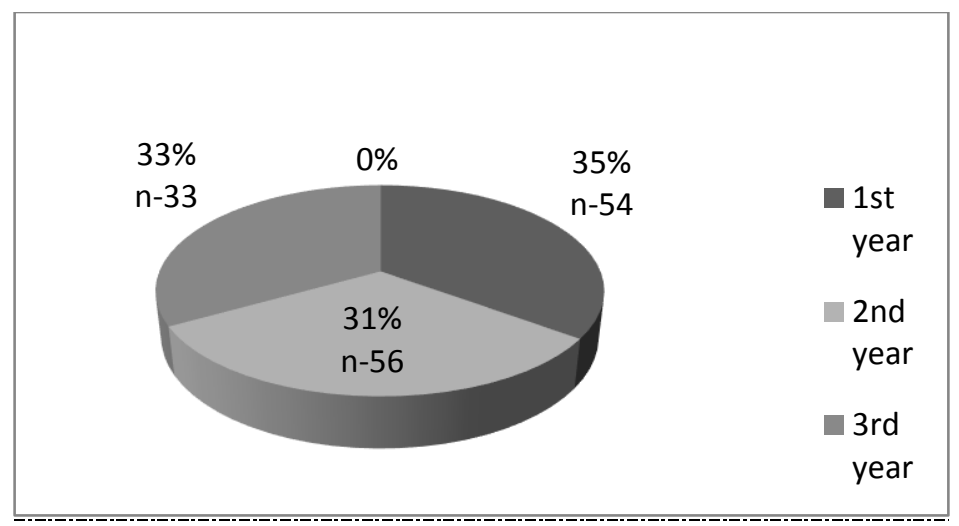

Table 3 - Depression severity amongst $1^{\text {st }}, 2^{\text {nd }}$ and $3^{\text {rd }}$ year MBBS students

\begin{tabular}{|c|c|c|c|c|}
\hline Year & Mild & Moderate & Moderate Severe & Severe \\
\hline $1^{\text {st }}$ Year & $26(32.5 \%)$ & $14(31.11 \%)$ & $5(50 \%)$ & $4(50 \%)$ \\
\hline $2^{\text {nd }}$ Year & $41(51.25 \%)$ & $16(35.56 \%)$ & $3(30 \%)$ & $2(25 \%)$ \\
\hline $3^{\text {rd }}$ Year & $13(16.25 \%)$ & $15(33.33 \%)$ & $2(20 \%)$ & $2(25 \%)$ \\
\hline Total & 80 & 45 & 10 & 8 \\
\hline Percentage & $40 \%$ & $22.5 \%$ & $5 \%$ & $4 \%$ \\
\hline
\end{tabular}




\section{DISCUSSION}

Medical Education renders significant amount of stress to the students. The proportion of stress among MBBS students is different for different year. In this study also $31.5 \%$ of the medical students had substantial amount of stress which is comparable to the other studies conducted at Brazil (40.2\%), Iran (44\%) and Malaysia (41.9\%) [16]. The substantial stress is estimated in those students whose PHQ-9 score is above 10 . The severe stress was just $4 \%$. Medical Students go through not only the stress imposed by medical education but also routine everyday life stressors which may explain the level of severe stress noted among medical students. This increased level of stress and consequently depression indicates a decrease of psychological health in our students which may impair students' behavior, diminish learning and ultimately affect patient care [17].

In our study prevalence of depression in $1^{\text {st }}$ year versus $2^{\text {nd }}$ year versus $3^{\text {rd }}$ year is as following $1^{\text {st }}$ year: $24.5 \%, 2^{\text {nd }}$ year: $31 \%, 3^{\text {rd }}$ year: $16 \%$. In our study, the prevalence of depression was found to be more in $1^{\text {st }}$ year than the $2^{\text {nd }}$ and $3^{\text {rd }}$ year. This finding could be due to students' just entering medical college after high school. The other causes maybe language problem, vast syllabus, fear of failure, tight schedule and tough topics. Medical Council of India also suggests foundation course of 2 months duration after admission to prepare a student to study medicine effectively. [18]. Also, it is seen that the prevalence of depression is lowest for $2^{\text {nd }}$ year students. This is probably due to long span of the $2^{\text {nd }}$ year and ample time for studies and to adjust with the surroundings. The prevalence of depression is $71 \%$ for $3^{\text {rd }}$ year students which is more than $3^{\text {rd }}$ year but less than $1^{\text {st }}$ year. Generally, it is seen that as the prevalence of depression to be found less in the clinical years than the non-clinical years [19]. Both the first and third year students reported academic stress and hectic life cycle as their principal stress inducing factors. Even studies from India and Pakistan reported academic stress and exam as the most troublesome stressors. But in the done in the Britain, students did not report of overload as their major source of stress [20].

In our study prevalence of Depression in Male versus Female students is as following - Depressed females $76 \%$, Depressed male - $65 \%$. Another finding of our study is that a gender difference regarding the association with depression was noted where female students reported a marginally higher prevalence of depression than in men. Other similar studies done by Davidson also report depression to be more in female students [21]. This gender Variation in depressive status in medical students could be reflection of usual trend of high prevalence of depression in females as in general population [22]. The finding of similar female: male prevalence ratios in developed countries and globally suggests that the differential risk may primarily stem from biological sex differences and depend less on race, culture, diet, education and numerous other potential social and economic factors [23].

In our study the prevalence of Depression in Hostelite versus Localite is as following i.e. Hostelite - $70 \%$ and Localite - 73\%. Hostelite- The students residing in the hostel and Localite - The students residing in the nearby locality in rented apartments or those living in their respective homes. It is noted that localities have slightly higher prevalence of depression than that of the hostelites. The probable reason maybe the transport through local trains which is very hectic and tiresome. They miss out the jolly life of the hostelites which can be the major reason of the higher prevalence of stress in them.

\section{CONCLUSION}

Interaction between students and faculties should be encouraged so that the signs of stress can be detected and addressed at the earliest. Prevention strategies should take into considerations the wide variety of factors that are inducing stress among students. Allowing flexible learning options in the curriculum may offer a variety of options including clinical electives, laboratory posting or community exposure in areas that students are not normally exposed as a part of regular curriculum. This can be the reason of low prevalence of depression in $2^{\text {nd }}$ year students. This will also provide opportunity for students to do project, enhance self-directed learning, critical thinking and research abilities.it is possible that few students have already an inherent tendency of taking stress and their entry in MBBS course maybe be aggravating it. Such students should be identified by psychological screening tests at the time of their entry only. Compulsory recreation facilities should be provided within the campus for the students as it is proved that 
inadequate social activity and impaired psychological health are interlinked and that leisure activities can reduce stress among students. Relaxing exercises, yoga and meditation should be studied to relieve stress among medical students

\section{REFERENCES}

1. Vaidya PM, Mulgaonkar KP. Prevalence of Depression Anxiety \& Stress In Undergraduate Medical Students \& Its Co Relation With Their Academic Performance. Indian J Occupational Ther 2007;39(1):7-10.

2. Chandavarkar U, Azzam A, Mathews CA. Anxiety symptoms and perceived performance in medical students. Depress Anxiety 2007;24(2):103-11.

3. Bayram N, Bilgel N. The prevalence and socio-demographic correlations of depression, anxiety and stress among a group of university students. Social Psych Psychiatr Epidemiol 2008;43(8):667-72.

4. Kumaraswamy N, Ebigbo PO. Stress among second year medical students: A comparative study. Indian Journal of Clinical Psychology 1989;16(1):21-3.

5. Dahlin M, Joneborg N, Runeson B. Stress and depression among medical students: A cross- sectional study. Med Education 2005;39(6):594-604.

6. Reddy VM, Chandrashekar CR. Prevalence of mental and behavioural disorders in India: A meta-analysis. Indian J Psychiatry 1998;40(2):149-57.

7. Zoccolillo M, Murphy GE, Wetzel RD. Depression among medical students. J Affect Disord 1986;11(1):916.

8. Dyrbye LN, Thomas MR, Shanafelt TD. Medical student distress: causes, consequences, and proposed solutions. Mayo Clinic Proc 2005;80(12):1613-22.

9. Ponnudurai R, Somasundaram O, Balakrishnan S, Srinivasan N. Depression: a study of 80 cases. Indian J Psychiatry 1981;23:256-8.

10. Dyrbye LN, Thomas MR, Shanafelt TD. Systematic review of depression, anxiety, and other indicators of psychological distress among US and Canadian medical students. Acad Med 2006;81(4):354-73.

11. Iqbal S, Gupta S, Venkatarao E. Stress, anxiety \& depression among medical undergraduate students \& their socio-demographic correlates. Indian J Med Res 2015;141(3):354-8.

12. Sidana S, Kishore J, Ghosh V, Gulati D, Jiloha RC, Anand T. Prevalence of depression in students of a medical college in New Delhi: a cross-sectional study. Australasian Med J 2012;5(5):247-50.

13. Sherina MS, Rampal L, Kaneson N. Psychological stress among undergraduate medical students. Med J Malaysia 2004;59(2):207-11.

14. Kroenke K, Spitzer RL, Williams JB. The PHQ- 9: validity of a brief depression severity measure. J Gen Intern Med 2001;16(9):606-13.

15. Kroenke K, Spitzer RL. The PHQ-9: a new depression diagnostic and severity measure. Psychiatr Ann 2002;32(9):509-15.

16. Abdulghani HM. Stress and depression among medical students: A cross sectional study at a medical college in Saudi Arabia. Pak J Med Sci 2008;24(1):12-6.

17. Rotenstein LS, Ramos MA, Torre M, Segal JB, Peluso MJ, Guille C, Sen S, Mata DA. Prevalence of depression, depressive symptoms, and suicidal ideation among medical students: a systematic review and meta-analysis. JAMA 2016;316(21):2214-36.

18. Llyod C, Gartell NK. Sex differences in the student's mental health. Am J Psychiatry 1981;138(10):1346-51.

19. Firth J. Levels and sources of stress in medical students. BMJ 1986;292(6529):1177-80.

20. Davidson V. Coping styles of women medical students. Med Educ 1978:53(11):902-7.

21. Andrews B, Wilding JM. The relation of depression and anxiety to life- stress and achievement in students. Br J Psychol 2004;95(4):509-21.

22. Albert PR. Why is depression more prevalent in women ?. J Psychiatr Neurosci 2015;40(4):219-25.

23. Rosenthal JM, Okie S. White coat, mood indigo-depression in medical school. New Engl J Med 2005;353(11):1085-8.

Acknowledgements - I am thankful to Management of MIMER MEDICAL COLLEGE, Talegaon (D), PHQ-9 Patient Depression Questionnaire, Department of Biochemistry/Psychiatry, My colleagues who participated in the project.

Conflict of Interest - Nil ; Funding - Nil 